\title{
Comparative Analysis of Architecture Research Article Abstracts Written by Native and Non- native Authors: A Cross-linguistic, Cross-cultural Study
}

\author{
Leila Noorizadeh-Honami \\ Department of English, Isfahan Branch, Islamic Azad University, Isfahan, Iran \\ Azizeh Chalak \\ Department of English, Isfahan Branch, Islamic Azad University, Isfahan, Iran
}

\begin{abstract}
It is increasingly becoming important to focus on the rhetorical aspects of texts used for creating different discourse types. In point of fact, the abstract section of scientific articles possesses a rhetorically defined structural framework which is very often culture specific. As such, the present study aimed to investigate the abstract section of the articles written by English and Persian authors, in order to explore whether they followed a similar structural pattern. To this end, a corpus of 60 English and Persian abstracts, thirty each, was randomly selected from English ISI journals and Iranian scientific journals and analyzed based on the IMRD framework introduced by Swales (1990). Findings of this study revealed that most English and Persian authors used the IMRD model in the structure of their abstracts; although, the frequency of occurrence of each move was different. In terms of moves' sequence, all the used patterns were analyzed and IM-R-D and I-M-R were identified as the most frequent patterns used in both groups. Findings of this study may have implications for Iranian authors who seek to publish their studies in reputable international journals.
\end{abstract}

Index Terms - abstract, move analysis, Swales' IMRD model

\section{INTRODUCTION}

Writing research articles for academic scholars who wish to publish the findings of their studies in prestigious and reputable English journals is of great significance. As Cortes (2004) mentioned, students need to be aware of conventional structures used in academic writings and merely exposing students to research articles would not lead to learning related writing skills. Consequently, in recent years numerous studies have been conducted on research articles' structure. Some studies such as Salager-Meyer (1992), Santos (1996), and Lau (2004) have investigated abstract sections of the research articles, others including Swales (1990) and Samraj (2002) have examined introductions.

Hyland (2004) pointed out the concept of genre has been gaining growing attention in the last decade. There are three different approaches to the concept of genre: New Rhetoric approach, ESP (English for Specific Purpose) approach, and Systemic Functional Linguistics. In the New Rhetoric approach Halliday (1994) focused on social functions of genres rather than forms. According to Paltridge (2001), in ESP genre is viewed as a communicative event, such as a scholarly article, which involves certain purposes within a specific community. As Paltridge (2001) put it, in Systemic Functional Linguistics a genre is a text which has related context, form, and function such as an argumentation or exposition. Hyland (2002), taking the same Systemic Functional Linguistics view, believed a genre is a conventional structure used in the interactions between the writer and his/her readers.

In recent years, even more definitions have been provided for the concept of genre. Van Dijk $(2008,2009)$ has a sociocognitive view towards genre. He believes that genres have different contexts which require a common schema and understanding in the related community. According to Parodi (2010), "a genre is a constellation of potential discourse conventions sustained by the previous knowledge of the speakers/writers and listeners/readers (stored in the memory of each subject), based on a contextual, social, linguistic, and cognitive possibilities and/or constraints." (p. 25). Moreover, as Graves, Moghaddasi, and Hashim (2013) asserted, there are two directions for genre studies; first direction which is concerned with research article sections such as abstract, introduction, etc., can develop students' academic writing skills, and the second one is concerned with the relationship between RA structure and the methods used in their discipline.

Swales (1990) viewed genre as "a class of communicative events, the members of which share some set of communicative purposes" (p. 58). He classified genres as having 'moves', which are obligatory, and 'steps' which are 
optional elements. Moreover, Swales and Feak (2009) defined genre as a type of discourse which seeks to obtain certain communicative purposes.

According to Lores (2004) 'abstract' is defined by the American National Standards Institute (ANSI) as: "an abbreviated accurate representation of the content of a document, preferably prepared by its author(s) for publication with it". Huckin (2001) describes abstracts in four ways, regarding their function: "stand-alone mini texts" because they provide a summary of the topic, method, and findings of the article for the readers; "screening devices" because they assist readers deciding whether the whole article is worth reading; "preview" because it indicates the order of materials presented in the article; and finally, "aids to indexing" (p. 93) because they provide easy access to information through being indexed in relevant database.

Martin (2003) asserted for publishing an article in almost all scholarly journals submitting the abstract is necessary. As Martin (2003) put it, a research article abstract functions as a "time-saving device" (p. 26) which enables readers decide on whether the entire article is worth reading. Moreover, research article abstracts are a means of promoting the article and persuading readers to read the entire article (Hyland, 2000; Hyland \& Tse, 2005). The significance of abstract is well indicated by Pho (2008) as a section which "sells" (p. 231) the article. Graetz (1985) asserted obtaining knowledge of linguistic structure and functions of abstracts can increase learners' understanding of different journal abstracts.

Significance of research article abstracts (RAAs), as a specific genre in academic communities has led to a large number of studies in various fields including Santos (1996) in applied linguistics; Melander, Swales, and Fredrickson (1997) in biology, medicine, and linguistics; Martin (2003) in experimental social sciences; Lores (2004); Samraj (2005); and Pho (2008) in applied linguistics. For example, Melander et al. (1997) conducted a study on the effect of academic field of study and national language on the general structure of English abstracts written by Americans and Swedes, alongside those written by Swedes in Swedish in three different fields namely biology, medicine, and linguistics. The results of their study proved the field of study had a greater influence on the organization of the abstracts.

There are three dominant approaches to genre analysis; first, the CARS model (Create A Research Space) introduced by Swales (1990) which was employed for analyzing research article introductions. Second, the IMRD model (Introduction, Methods, Results, and Discussion) proposed by Swales (1990) which was applied to analyze research article abstracts. Finally, Hyland (2004) introduced a five-move framework termed the IPMPrC model (Introduction, Purpose, Method, Product, Conclusion).

Lores (2004) introduced two types of abstracts namely "informative", which follow IMRD pattern, and "indicative", which follow CARS model. She investigated 36 research article abstracts from three journals in the field of linguistics. Findings of this study indicated that most abstracts had the IMRD model as their basis rather than CARS.

In recent years, there has been an increasing amount of literature on analyzing different sections of research articles and in particular abstracts. For instance, Martin (2003) compared abstracts written by English and Spanish authors and discovered that IMRD structure was used in most abstract, although the Result move was omitted in some Spanish abstracts.

Moreover, in their comparative study, Jeon and Eun (2007) investigated ten doctoral dissertation abstracts written by Korean and American writers, five each, based on IMRD structure and found that the IMRD was similarly followed by all writers.

In a recent cross-cultural, cross-disciplinary study Wang and Tu (2014) investigated a corpus of 1000 RAAs regarding CARS, IMRD, and IPMPrC frameworks. Findings of their study revealed that the IMRD framework was employed in $53.9 \%$ of the RAAs which indicated a greater tendency among writers to use this framework.

Findings of a genre analysis study conducted on research articles in Persian by Marefat and Mohammadzadeh (2013) investigated both IMRD and CARS patterns in 90 English and Persian abstracts in Literature and found that Persian abstracts generally followed CARS model although showing some deviations.

In another study, Chalak and Norouzi (2013) investigated 40 RAAs written by American and Iranian authors, 20 each, in terms of rhetorical moves based on Swales and Feak (2009) model and found that both groups of authors used moves Purpose, Method, and Results more than Introduction and Conclusion.

Limited number of cross-linguistic studies on RAAs written in Persian and English, was the rationale behind conducting the present research, which attempts to familiarize Iranian novice writers with structures used in international research communities. To obtain this goal, abstract section of 60 English and Persian RA were analyzed according to Swales' (2004) CARS model to find out how and to what extent Persian and English scholars utilize this pattern in their writings. Thus, this research seeks to address the following questions:

1. What rhetorical structures are used in English and Persian RAAs in the field of Architecture?

2. Is there any recognizable pattern in the utilization of IMRD employed in English and Persian architecture RAAs regarding the sequence in which they appear?

\section{Methodology}


In the present study, 30 English and 30 Persian research articles in Architecture were investigated in terms of using Swales' (1990) IMRD framework. In selecting the English RAs, in order to achieve more reliable results, both nationality of the writers and scientific level of the journals they were published in, were carefully controlled. Consequently, English articles written by English native speakers and published in ISI journals such as Frontiers of Structural and Civil Engineering and Building and Environment were selected. In the selection of Persian RAs, journals' availability was an important factor; therefore, RAAs written by Persian native speakers and published in Iranian academic journals such as Baagh-e-Nazar and Saakht-e-Shahr were analyzed. All the investigated RAAs were published within 2010 to 2014.

\section{B. Instruments}

For the purpose of moves' analysis, Swales' (1990) IMRD framework was employed. This framework has been effectively used by many scholars including Martin (2003), Lores (2004), Van Bonn and Swales (2007), and Lim (2010). According to this framework, the Introduction move involves the purpose, objectives, statement of the problem and the rationale for conducting the study; the Method move indicated the methodology, materials, participants, data collection, procedures, and statistical analysis; the Result move contains statements on general findings of the study; and finally, the Discussion move presents interpretation of the results, implications of the findings, and suggestions for further research. So, as to clarify the moves analyses conducted in the study, some examples adopted from English RAAs are provided below.

Example 1:

Introduction: This paper is aimed to provide a general overview of the current state of research concerning structural robustness.

Example 2:

Methods: The accuracy of the developed model is investigated by solving an experimental dam-break test case.

Example 3:

Results: At a certain slenderness ratio, the stability factor first decreases and then increases with temperature rise.

Example 4:

Discussion: Great improvement can be revealed by contrasting the results of the CWDB model with those of the Ritter's solution.

\section{Data Collection Procedure}

As the first phase of the study, moves analysis was applied based on the content of the texts. In order for clear identification of moves employed in both English and Persian RAAs, two main steps were followed: firstly, each abstract was skimmed entirely in order to obtain an overall understanding of the text; secondly, they were scanned for the presence of moves based on Swales' (1990) IMRD model. Although, some researchers in the field of rhetorical moves such as Mizuta, Mullen, and Collier (2004) (as cited in Pho, 2008), argued that the smallest unit of analysis is a phrase, in the present study given the brevity of abstracts, the frame of reference recognized for the moves analysis ranged from a single word to a phrase or a sentence. Consequently, more than one move was recognized in most sentences. Hence, the order of moves' appearance was taken into account in analyzing move's patterns.

The second phase of the study included detailed analysis of sequence of moves used in all English and Persian RAAs in order to investigate whether they followed linear, i.e., I-M-R-D, or nonlinear, e.g., I-R-M-D, pattern. Considering Paltridge's (1994) claim regarding subjectivity of content based analyses, to avoid subjectivity in moves' identification all the abstracts were analyzed by two experienced English instructors and the inter-rater reliability coefficient $86 \%$ was obtained.

\section{Data Collection Procedure}

In order to identify the probable commonalities and differences between the two groups of English and Persian RAAs, first frequency and percentage of the Moves employed in each abstract was determined. The obtained nonparametric data, then, were analyzed through Chi-Square to discover whether the differences across the two groups of RAAs were statistically significant. Second, the sequences of moves, identified as linear and nonlinear, were analyzed through calculating frequency and percentage.

\section{RESULTS AND DISCUSSION}

Concerning the first research question, in order to ascertain the commonalities and differences of macrostructures utilized in English and Persian RAAs in the field of architecture, Swales' (1990) IMRD model was used. First, the frequency and percentage of occurrence of each move was computed in all RAAs. Second, to investigate the differences in the groups regarding move's application, the findings were compared through employing Chi-square. The results of this comparative analysis are presented in Table 1. 
TABLE 1.

FREQUENCY AND PERCENTAGE OF IMRD MOVES IN ALL ABSTRACTS

\begin{tabular}{llllllll}
\hline Moves & Number of & \multicolumn{2}{l}{ English RAAs } & \multicolumn{2}{c}{ Persian RAAs } & \multicolumn{2}{c}{ Chi-Square } \\
\cline { 2 - 8 } & Abstracts & F & $\%$ & F & $\%$ & $\chi 2$ & Sig. \\
\hline I & 30 & 52 & 28.3 & 132 & 71.7 & 34.78 & $<.001$ \\
M & 30 & 91 & 56.5 & 70 & 43.5 & 2.74 & .098 \\
R & 30 & 35 & 43.2 & 46 & 56.8 & 1.49 & .222 \\
D & 30 & 14 & 33.3 & 28 & 66.7 & 4.67 & .031 \\
\hline
\end{tabular}

As depicted in Table 1, the most noticeable difference was observed in the occurrence of move Introduction where the Persian and English authors attempted to introduce the objectives of their study. The second noticeable difference was observed in the application of move Method which presents methodology, participants, and data collection method. Regarding moves Results and Discussion, the results revealed a relatively less difference. Nonetheless, in order to discover whether these differences were statistically significant, a Chi-square test was applied.

In order to answer the first research question, the results of the Chi-square test were analyzed. According to the results of the Chi-square test, as presented in Table 1, there was a statistically significant difference $(p<0.05)$ in the occurrence of move Introduction between English and Persian RAAs. Moreover, considering move Discussion, a statistically significant difference $(p<0.05)$ was observed between the two groups. However, analysis of moves Method and Results, revealed no significant difference $(p>0.05)$ between the two groups.

Analyzing the results, it was revealed that Introduction and Discussion moves were noticeably used more in Persian than in English RAAs, while there was no significant difference in the application of Method and Result moves in the corpus. As indicated by the results of the study, the occurrence of the Introduction move in the Persian RAAs was drastically more than the English ones. This might be due to either socio-cultural factors such as cultural patterns which require enormous explanations, or the lack of appropriate academic writing instructions.

With regard to the second research question, sequence of the moves employed in all RAAs was explored to find out whether they followed the I-M-R-D linear pattern. As it is depicted in Table 2, the I-M-R-D linear sequence was found in one-third of English RAAs, and half of Persian ones. The result of the Chi-square test, however, revealed no significant difference $(p>0.05)$ in the corpus regarding the sequence of moves.

TABLE 2.

THE LiNEAR SEQUENCE IN All ABSTRACTS

\begin{tabular}{llllllll}
\hline & \multicolumn{8}{c}{ THE LINEAR SEQUENCE IN ALL ABSTRACTS } \\
\cline { 3 - 7 } & & English RAAs & $\%$ & Persian RAAs & \multicolumn{2}{c}{ Chi-Square } \\
\hline \multirow{2}{*}{ IMRD } & No & 20 & 66.7 & 15 & 50.0 & & Sig. \\
& Yes & 10 & 33.3 & 15 & 50.0 & 1.714 & .190 \\
\hline Total & & 30 & 100.0 & 30 & 100.0 & & \\
\hline
\end{tabular}

Moreover, all the other sequences used in the RAAs, were identified. According to Table 3., after I-M-R-D, the most frequent pattern recognized was I-M-R, which was used in approximately half of English and nearly one-third of Persian RAAs. The least frequent nonlinear patterns were I-M-R-M-R, M-I-M-R, M-I-M-R-D, and M-I-M-R-M-D which were recognized in $3.3 \%$ of English RAAs.

TABLE 3.

SEQUENCE OF LINEAR AND NONLINEAR MOVES

\begin{tabular}{lllll}
\multicolumn{5}{c}{ SEQUENCE OF LINEAR AND NONLINEAR MOVES } \\
\cline { 2 - 5 } & English RAAs & \multicolumn{3}{l}{ Persian RAAs } \\
\cline { 2 - 5 } IMRD & $\mathrm{F}$ & 33.3 & $\mathrm{~F}$ & 50.0 \\
IMR & 10 & 46.7 & 9 & 30.0 \\
IMRMD & 14 & 6.7 & 0 & 0.0 \\
IMRMR & 2 & 3.3 & 0 & 0.0 \\
MIMR & 1 & 3.3 & 0 & 0.0 \\
MIMRD & 1 & 3.3 & 0 & 0.0 \\
MIMRMD & 1 & 3.3 & 0 & 0.0 \\
IMD & 1 & 0.0 & 2 & 6.7 \\
IMIRD & 0 & 0.0 & 2 & 6.7 \\
IR & 0 & 0.0 & 2 & 6.7 \\
\hline Total & 0 & 100.0 & 30 & 100.0 \\
\hline
\end{tabular}

Occurrence of the I-M-R-D linear pattern which was used in half of Persian RAAs and one-third of English ones may imply that Persian authors are more conservative in following the conventional standard linear pattern than the English authors. The results of this study were in line with several studies including Jeon and Eun (2007), Martin (2003), and Wang and Tu (2014).

\section{CONCLUSION}

The present study attempted to investigate whether there was any statistically significant difference in the RAAs written by English and Persian authors in terms of following Swales' (1990) IMRD framework. Additionally, it was 
intended to discover whether the patterns used were linear or nonlinear. To this end, RAAs written by Persian authors and English native authors were collected and analyzed. Findings of this study revealed some similarities and differences between the two groups. Based on the statistical analysis it was concluded that Persian authors preferred to provide more information in their Introduction and Discussion moves compared to English authors. On the other hand, English authors presented more information in their Method move.

Regarding the sequence of moves, it was found that the most frequent sequence observed in both groups was the IM-R-D linear sequence, although some variations were noticed in the corpus. Since each discourse community may use a particular genre structure in their research articles, it is necessary for academic authors to learn and employ those conventional rules that are accepted in their field. The evidence from this study can provide insights for Persian novice authors to improve their academic writing and obtain more opportunities for publishing their research articles in prestigious scientific journals. Nonetheless, it should be mentioned that this study was confined to one specific discipline and exploring RAAs in different disciplines may reveal other interesting and helpful results.

\section{REFERENCES}

[1] Chalak, A., Norouzi, Z. (2013). Rhetorical moves and verb tense in abstracts: A comparative analysis of American and Iranian academic writing. International Journal of Language Studies, 7(4), 101-110.

[2] Cortes, V. (2004). Lexical bundle in published and student disciplinary writing: Examples from history and biology. English for Specific Purposes, 23, 379-423.

[3] Graetz, N. (1985). 'Teaching EFL students to extract structural information from abstracts', in J.M. Ulijn and A. K. Pugh (eds) Reading for Professional Purposes: Studies and Practices in Native and Foreign Languages, pp. 123-35. London: Heinemann Educational Books.

[4] Graves, H., Moghaddasi, Sh., \& Hashim, A. (2013). Mathematics is the method: Exploring the macro-organizational structure of research articles in mathematics. Discourse Studies, 15(4), 421-438.

[5] Halliday, M. A. K. (1994). An introduction to functional grammar. London: Edward Arnold.

[6] Huckin, T. (2001). Abstracting from abstracts, in M. Hewings (ed.) Academic Writing in Context, pp. 93-103. Birmingham: University of Birmingham Press.

[7] Hyland, K. (2000). Disciplinary Discourses: Social Interactions in Academic Writing. London: Longman.

[8] Hyland, K. (2002). Genre: Language, context and literacy. Annual Review of Applied Linguistics, 22, 113-135.

[9] Hyland, K. (2004). Graduates' gratitude: The generic structure of dissertation acknowledgements. English for Specific Purposes, 22(3), 303-324.

[10] Hyland, K., \& Tse, P. (2005). Hooking the reader: A corpus study of evaluative that in abstracts. English for Specific Purposes, 24(2), 123-139.

[11] Jeon, B. M., \& Eun, H. Y. (2007). A contrastive rhetoric of doctoral dissertation abstracts written by American writers and Korean writers. The Linguistic Association of Korea Journal, 15(3), 161-188.

[12] Lau, H. H. (2004). The structure of academic journal abstracts written by Taiwanese PhD students. Taiwan Journal of TESOL, $1(1), 1-25$.

[13] Lim, J. M. H. (2010). Commenting on research results in applied linguistics and education: A comparative genre-based investigation. Journal of English for academic Purposes, 9(4), 280-294.

[14] Lores, R. (2004). On RA abstracts: from rhetorical structure to thematic organization. English for Specific Purposes, 23, 280302.

[15] Marefat, H., \& Mohammadzadeh, Sh. (2013). Genre analysis of literature research article abstracts: A cross-linguistic, crosscultural study. Applied Research on English Language, 2(2), 37-50.

[16] Martin, P. M. (2003). A genre analysis of English and Spanish research paper abstracts in experimental social sciences. English for Specific Purposes, 22(1), 25-43.

[17] Melander, B., Swales, J. M., \& Fredrickson, K. M. (1997). Journal abstracts from three academic fields in the United States and Sweden: National or disciplinary proclivities, in A. Duszac (ed.), Culture and Styles of Academic Discourse, Berlin: Mouton De Gruyter, pp. 251-272.

[18] Mizuta, Y., Mullen, T. and Collier, N. (2004) 'Annotation of Biomedical Texts for Zone Analysis', National Institute of Informatics Technical Report NII-2004-007 E.

[19] Paltridge, B. (1994). Genre Analysis and the Identification of Textual Boundaries. Applied Linguistics, 15(3), $288-299$.

[20] Paltridge, B. (2001). Genre and the language learning classroom. Ann Arbor, MI: The University of Michigan Press.

[21] Parodi, G. (Ed.). (2010). Academic and professional discourse genres in Spanish (Vol. 40). Amsterdam, The Netherlands: John Benjamins Publishing.

[22] Pho, P. D. (2008). Research article abstracts in applied linguistics and educational technology: A study of linguistic realizations of rhetorical structure and authorial stance. Discourse Studies, 10(2), 231-250.

[23] Salager-Meyer, F. (1990). Discoursal flaws in medical English abstracts: A genre analysis per research- and text-type. Text, 10(4), 365-84.

[24] Salager-Meyer, F. (1992). A text-type and move analysis study of verb tense and modality distributions in medical English abstracts. English for Specific Purposes, 11, 93-133.

[25] Samraj, B. (2002). Introductions in research articles: Variations across disciplines. English for Specific Purposes, 21(1), 1-17.

[26] Samraj, B. (2005). An exploration of a genre set: research article abstracts and introductions in two disciplines. English for Specific Purposes, 24, 141-156.

[27] Santos, M. B. D. (1996). The textual organization of research paper abstracts in applied linguistics. Text, 16, 481-499.

[28] Swales, J. M. (1990). Genre analysis: English in academic and research settings. Cambridge: Cambridge University Press.

[29] Swales, J. M. (2004). Research Genres: Exploration and Applications. Cambridge: Cambridge University Press. 
[30] Swales, J. M, \& Feak, C. B. (2009). Academic writing for graduate students. Ann Arbor: University of Michigan Press.

[31] Van Bonn, S., \& Swales, J. M. (2007). English and French journal abstracts in the language sciences: Three exploratory studies. Journal of English for Academic Purposes, 6(2), 93-108.

[32] Van Dijk, T. A. (2008). Discourse and Context. A Sociocognitive Approach. Cambridge: Cambridge University Press.

[33] Van Dijk, T. A. (2009). Society and Discourse: How Social Contexts Influence Text and Talk. Cambridge: Cambridge University Press.

[34] Wang, S. P., \& Tu, P. N. (2014). Tense use and move analysis in journal article abstracts. Taiwan Journal of TESOL, 11(1), 329.

Leila Noorizadeh-Honami (Email: iaunfaculty@yahoo.com) is a PhD candidate of TEFL at the English Department of Islamic Azad University, Isfahan (Khorasgan) Branch, Isfahan, Iran. Her research interests include Information and Computer Technology (ICT), Genre Studies, E-learning.

Azizeh Chalak (Email: azichalak@gmail.com) is an assistant professor of TEFL at the English Department of Islamic Azad University, Isfahan (Khorasgan) Branch, Isfahan, Iran. Her research interests include Discourse Analysis, Sociolinguistics, Intercultural Communication, E-mail Communications, Computer-Mediated Communication (CMC), Genre Studies, and Methods of Teaching. 